\title{
Europe overhauls physician mobility regulations
}

A

lerts about previous fitness to practice sanctions, a "professional card" for doctors and language competency criteria are among measures proposed by the European Commission to govern movement of physicians between nations.

The measures will simplify the process of recognizing the professional qualifications of physicians and promote mobility, the commission argues in its Proposal for a Directive of the European Parliament and of the Council amending Directive 2005/36/EC on the recognition of professional qualifications and Regulation on administrative cooperation through the Internal Market Information System (http://ec .europa.eu/internal_market/qualifications /docs/policy_developments/modernising /COM2011_883_en.pdf).

The fitness-to-practice alert, which will require countries to inform one another when a physician has faced sanctions in his home nation, will "reinforce patient safety by obliging competent authorities to alert their counterparts throughout the European Union [EU] about health professionals who have been prohibited from exercising the profession in their territory," Chantal Hughes, spokesperson for the European Commissioner responsible for Internal Market and Services, writes in an email.

The professional card, meanwhile, will serve as a de facto assertion by the physician's home nation that he is qualified by "a competent authority" to practice medicine. Physicians so recognized will be listed on an online Internal Market Information System to which all member states must contribute. Use of the card is projected to reduce the time it currently to takes to recognize physician credentials to 6 weeks from 12 , as well as reduce costs for physicians seeking to set up their shingle in another country.

The changes may increase mobility, Dr. Konstanty Radziwill, president of the Standing Committee of Euro-

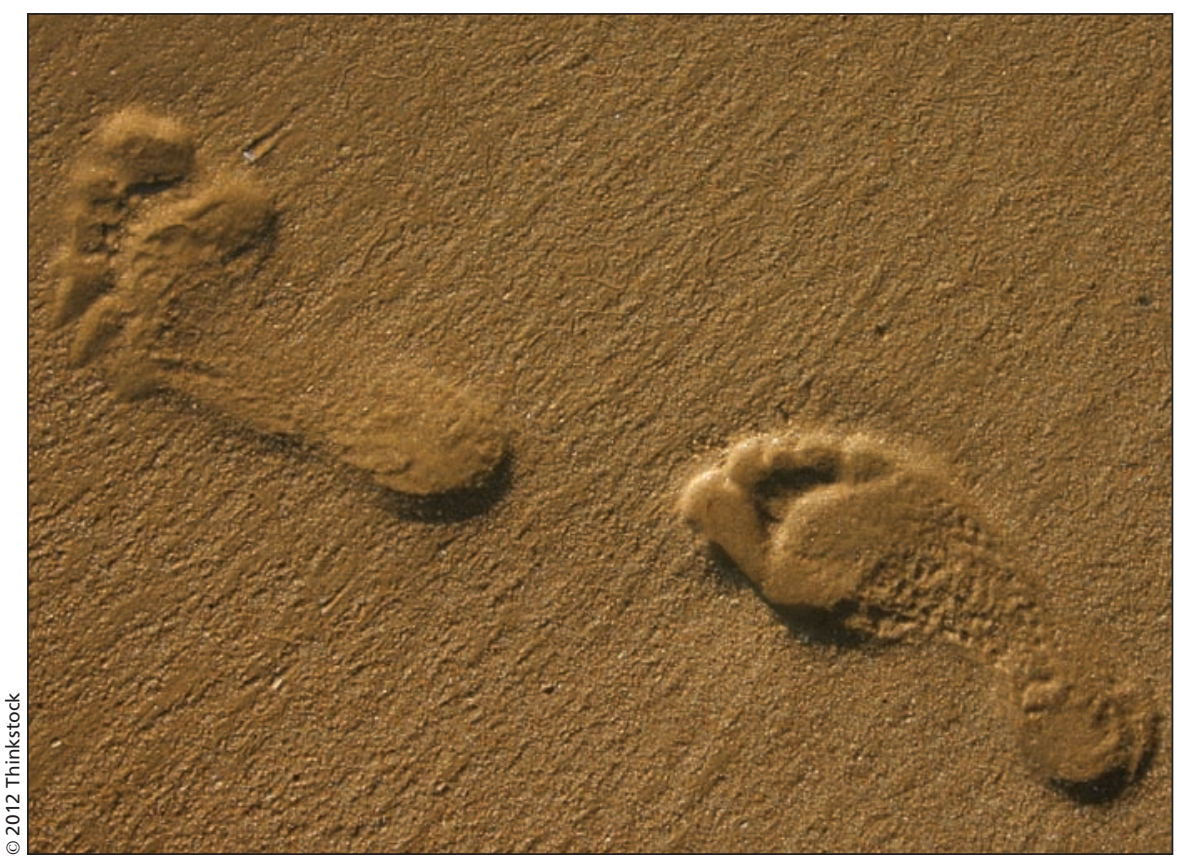

The European Union has taken steps to simplify the process of recognizing the professional qualifications of physicians to make it easier for doctors to walk away from practice in one member state to set up a shingle in another.

pean Doctors, writes in an email. "With a further need of clarification regarding the idea of the European professional card/e-Certificate, it is possible to ease doctors mobility and recognition."

But not all are convinced. Ongoing concerns over competency may have led "to the introduction of unreliable criteria and guarantees in order to recognise, homologate or adequately demonstrate professional competence, fitness to practice and the values of medicine," Dr. Jerónimo Torrente, deputy secretary general of the Spanish Medical Association, writes in an email.

Easier migration won't necessarily result, Dr. Pieter van den Hombergh, senior policy adviser for the Dutch National Association of General Practitioners, writes in an email. "Differences in training, CME [continuing medical education] and above all language and health care systems make free movement difficult mainly from the point of patient safety. The problem with this EU proposal is that countries don't agree, don't trust each other's training and competence, and have very good reasons to worry about patient safety, especially when language is not sufficient. So they don't agree on central exams (like the United States) and the possibility of a European diploma and CME requirements."

Others argue patient safety concerns weren't adequately addressed. "I am not sure that the reliance on the professional card is a great idea. There will be problems with validation and therefore risks of poor usage. This is not good for patient safety," Dr. Terry John, chairman of the International Committee of the British Medical Association, writes in an email. John, though, is pleased with reporting requirements and the fact that "the alert mechanism will apply to all countries."

Others believe there will be a net benefit for physicians. The advantages "outnumber the "bits and bobs"," Dr. Per Kallestrup, initiator of the European Exchange Programme for Medical Doctors Specializing in General 
Practice/Family Medicine and associate professor at the Centre for Global Health at Aarhus University in Denmark, writes in an email. "Different inputs is nurturing for professional training and the European public is far wiser than the professionals in order for them to be endangered. Protectionism and isolation is much more dangerous."
The language provisions allow member states to test the language skills of migrating physicians to ensure that they can adequately communicate with patients, while the minimum training requirements specify that basic medical training must be of at least five years duration and include a minimum 5500 hours of theoretical and practical instruction by a university. Each mem- ber state will have to appoint a national body to gauge if a physician has met the minimum training requirements. National authorities will also have to report regularly on "continuing education and training procedures" for doctors. - Tiago Villanueva Gutierrez Arruda Marques MD, Lisbon, Portugal

CMAJ 2012. DOI:10.1503/cmaj.109-4106 